\title{
Design of Reconfigurable Band Notches Antenna for Cognitive Radio Applications
}

\author{
Hicham Lalj ${ }^{1,2}$, Hafid Griguer'2, M'hamed Drissi ${ }^{1}$ \\ ${ }^{1}$ UEB, INSA of Rennes, IETR, Rennes, France \\ ${ }^{2}$ EMSI of Rabat, Rabat, Morocco \\ Email: hicham3076@gmail.com
}

Received 16 April 2014; revised 27 May 2014; accepted 18 June 2014

Copyright (C) 2014 by authors and Scientific Research Publishing Inc.

This work is licensed under the Creative Commons Attribution International License (CC BY). http://creativecommons.org/licenses/by/4.0/

c) (i) Open Access

\begin{abstract}
In this paper, an antenna with reconfigurable band notches, for cognitive radio applications, is proposed. The antenna can be operated as ultra wideband, and is reconfigurable in terms of the ability to select a notched band in the SRR resonant frequency. The reconfigurable band notches are induced using a band-stop filter based on split-ring resonators (SRRs), and are controlled using electronic switches mounted over the SRRs. For this sake, the design of the band-stop filter is proposed. A prototype of filter is fabricated and measured. The incorporation of a band-stop filter, into a wideband antenna, is then looked into. The proposed antenna is designed and simulated using Ansoft HFSS. A prototype of the antenna is fabricated and measured. A good analogy between simulated and measured results is obtained.
\end{abstract}

\section{Keywords}

Metamaterials, Band-Stop Filter, Split Ring Resonator (SRR), Band Notches Antenna

\section{Introduction}

Antennas have become a necessary and critical component of all personal electronic devices, microwave and satellite communication systems. In many of these systems, there is a requirement to perform a multitude of functions across several frequency bands and operating band widths, especially in the area of cognitive radio.

According to the Federal Communications Commission (FCC), a cognitive radio is "a radio that can change its transmitter parameters based on interaction with the environment in which it operates" [1] [2]. Thus, in cognitive radio system, we need the capability to sense the spectrum ("sensing" antenna), and communicate ("reconfigurable communicating" antenna). For these reasons, several antenna configurations have been developed for cognitive radio applications. In [3], a combination of wideband and narrowband antennas into the same 
volume is presented. The wideband antenna is a CPW fed printed hour-glass shaped monopole. The narrow band antenna is a microstrip patch printed on the reverse side of the substrate, and connected to the wideband antenna via a shorting pin. The authors in [4] discuss some of the possible antenna requirements for cognitive radio applications and outline some design approaches. In [5], the split-ring resonators [6] are employed in the design of UWB antennas with fixed notched bands. The authors in [7] present a design of a band notches antenna based on a ring slot etched in the patch.

In this paper, we propose an antenna for cognitive radio applications. It can be operated as ultra wideband and is reconfigurable in terms of the ability to select a notched band in the SRR resonant frequency. The rest of the paper is organized as follows. In Section 2, we propose a design of a bands top filter based on SRRs etched close to the microstrip line. In Section 3, we present the design of the proposed antenna, and we discuss the simulated and measured obtained results, and finally the paper is concluded in Section 4.

\section{Band-Stop Filter Design}

A microstrip transmission line is associated with a split ring resonator (SRR). The incident magnetic field needs to be polarized in the axial direction of the resonator, in this way, the resonator must be etched as close as possible to the line to increase the magnetic coupling. Accordingly, a band-stop phenomenon will appear in the vicinity of the SRR resonant frequency.

The SRR unit cell was designed to operate around $6.2 \mathrm{GHz}$. The geometry of the cell is as follows: $\mathrm{c}=\mathrm{d}=0.3$ $\mathrm{mm}, \mathrm{g}=0.6 \mathrm{~mm}$ and the global size is $4.6 \mathrm{~mm} \times 4.6 \mathrm{~mm}$ (Figure $1(\mathrm{a})$ ).

The substrate used is a RT/Duroid having the following characteristics (relative permittivity $\varepsilon \mathrm{r}=2.2$, loss tangent $\operatorname{tg}(\varphi)=0.0001$ and thickness $\mathrm{h}=0.8 \mathrm{~mm}$ ).

Figure 1(b) shows the [S] parameters simulated results. It shows a rejected frequency band around the designed frequency of the SRR resonator explained by a transmission of about $-25 \mathrm{~dB}$.

The proposed filter as shown in Figure 2 is based on a $50 \Omega$ line and a SRR unit cell etched close to the microstrip line designed in the microstrip technology. Figure 3 presents the band-stop filter simulated results. It has a central frequency of $6.2 \mathrm{GHz}$ and a rejection band as $600 \mathrm{MHz}$, a rejection band ( $\mathrm{S} 21=-10 \mathrm{~dB}$ ) is obtained in the designed frequency with low return loss.

The band-stop filter was fabricated, as shown in Figure 4. AGILENT TECHNOLOGIE-N5230A vector network analyzer was used to measure the response of the proposed filter and the results are shown in Figure 3.

A very good agreement is obtained between simulated and measured results.

\section{Reconfigurable Band Notches Antenna}

Depicted in Figure 5, the antenna is a monopole printed.

In a RT/Duroid having the following characteristics (relative permittivity $\varepsilon \mathrm{r}=2.2$, loss tangent $\operatorname{tg}(\varphi)=0.0001$ and thickness $\mathrm{h}=0.8 \mathrm{~mm}$ ), and features a partial rectangular ground plane. A tapered matching section was incorporated between the patch of the antenna and its feed line in order to achieve better impedance matching.

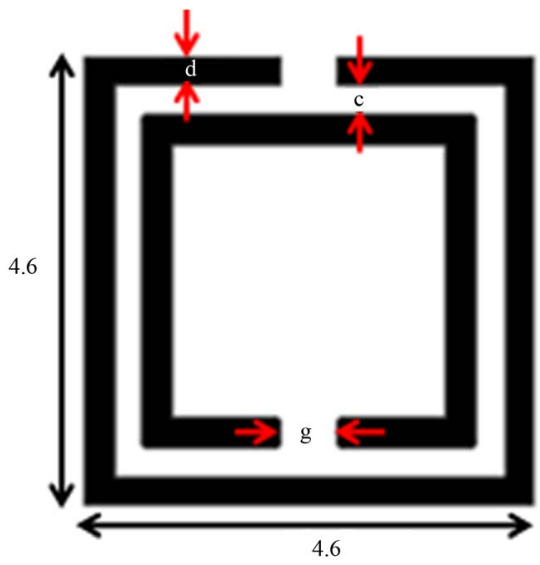

(a)

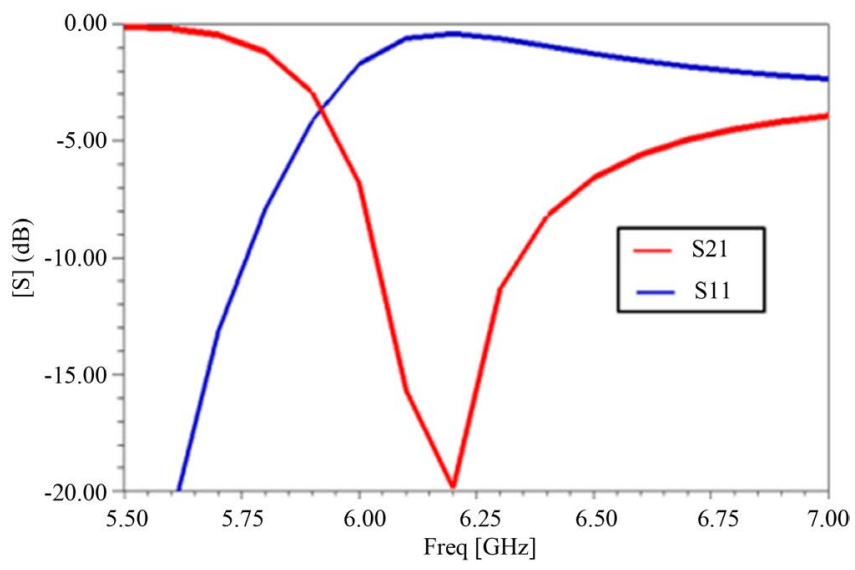

(b)

Figure 1. (a) SRR unit cell; (b) Simulated S parameters results. 


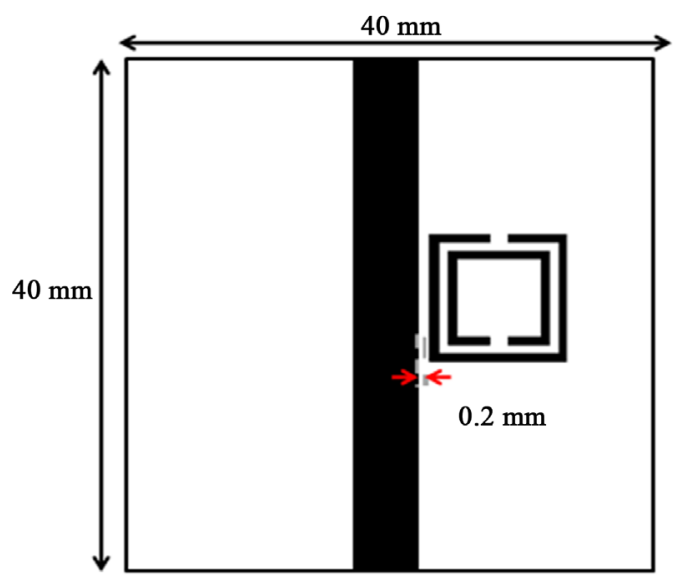

Figure 2. Design of band-stop filter based on SRR.

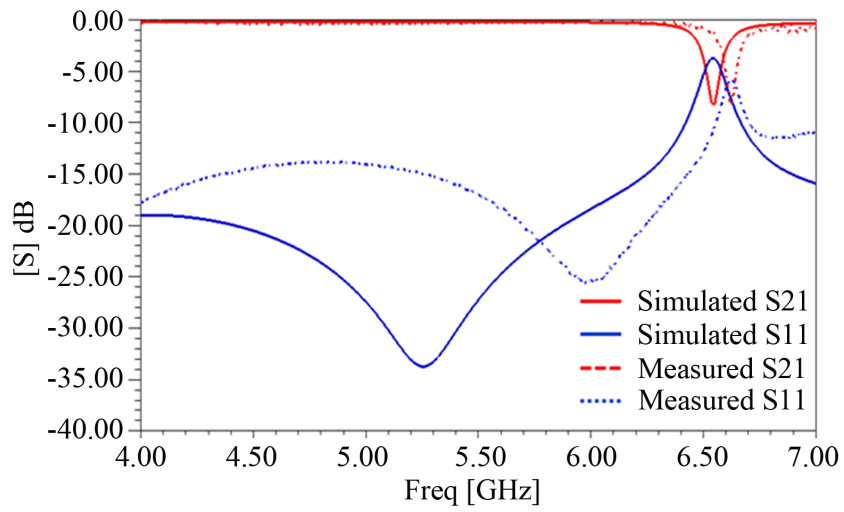

Figure 3. Simulated and measured S parameters for band-stop filter.

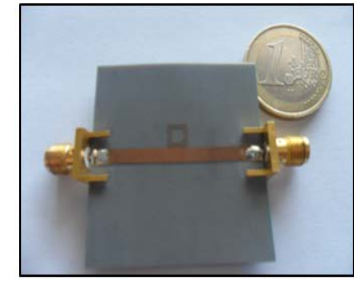

(a)

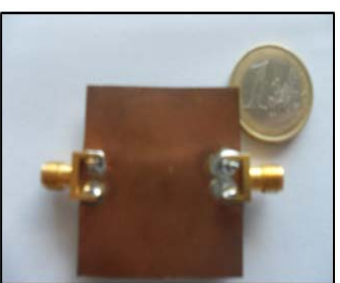

(b)

Figure 4. Photograph of the fabricated filter (a) Top plane; (b) Bottom plane.

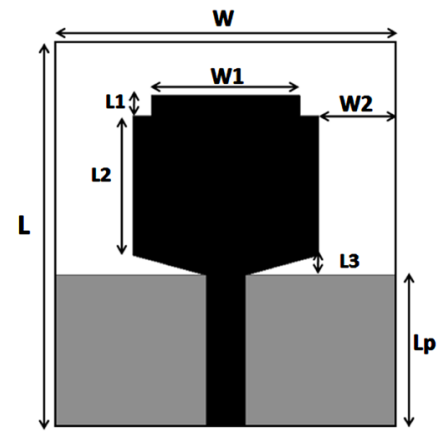

Figure 5. Design of monopole antenna. 
The different geometric parameters of the antenna are depicted in Table 1.

Figure 6 presents the antenna simulated S11 results. The reflection coefficient of the antenna is $\ll-10 \mathrm{~dB}$ over the 4 - $10 \mathrm{GHz}$ band.

The monopole antenna was fabricated, as shown in Figure 7. AGILENT TECHNOLOGIE-N5230A vector network analyzer was used to measure the response of the proposed filter and the results are shown in Figure 6.

A very good agreement is obtained between simulated and measured results.

The normalized simulated and measured radiation patterns for the monopole antenna are shown in Figure 8. The antenna has omnidirectional patterns and good gain value, the peak gain at the $6.2 \mathrm{GHz}$ is $5 \mathrm{~dB}$.

To induce band notches, both the band-stop filter and the UWB antenna was assembled in a single structure, two identical rectangular split rings are placed close to the microstrip line feed. Their sizes are optimized to cause a notch in the $6 \mathrm{GHz}$ band. To enable band notch reconfigurability, two electronic switches S1 and S2 are mounted over the split-ring resonators, as shown in Figure 9. It operates in parallel. That is, they are both ON or both OFF.

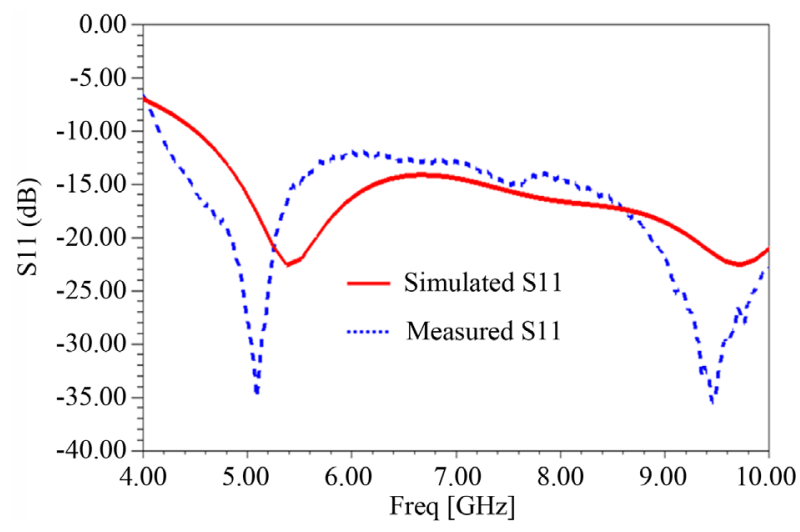

Figure 6. Simulated and measured S parameters for the monopole antenna.

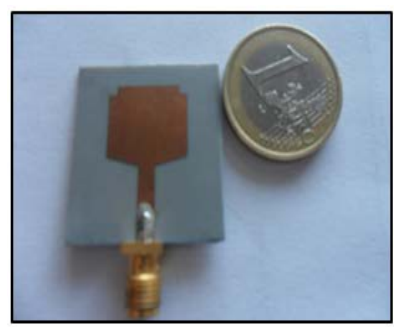

(a)

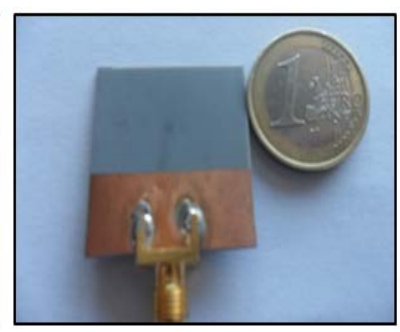

(b)

Figure 7. Photograph of the fabricated monopole antenna (a) Top plane; (b) Bottom plane.

Table 1. The geometric parameter of the monopole antenna.

\begin{tabular}{cc}
\hline Parameter & Value $(\mathrm{mm})$ \\
\hline W & 28 \\
L & 29 \\
L1 & 1.5 \\
L2 & 10.5 \\
L3 & 1.5 \\
W1 & 12 \\
W2 & 6.5 \\
Lp & 11.5 \\
\hline
\end{tabular}


..... E Plan: Measured

— E Plan : Simulated

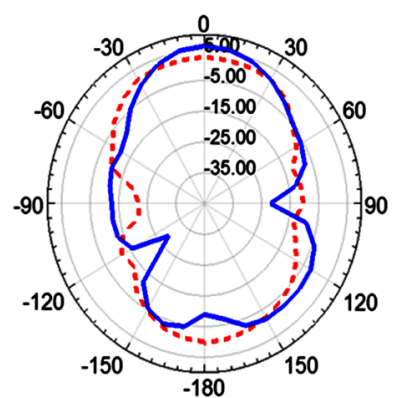

..... H Plan: Measured

— H Plan: Simulated

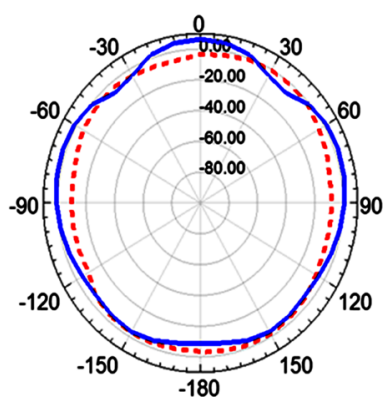

Figure 8. Simulated \& measured radiations pattern at $6.2 \mathrm{GHz}$ for the monopole antenna in the $\mathrm{E}$, and $\mathrm{H}$ plane.

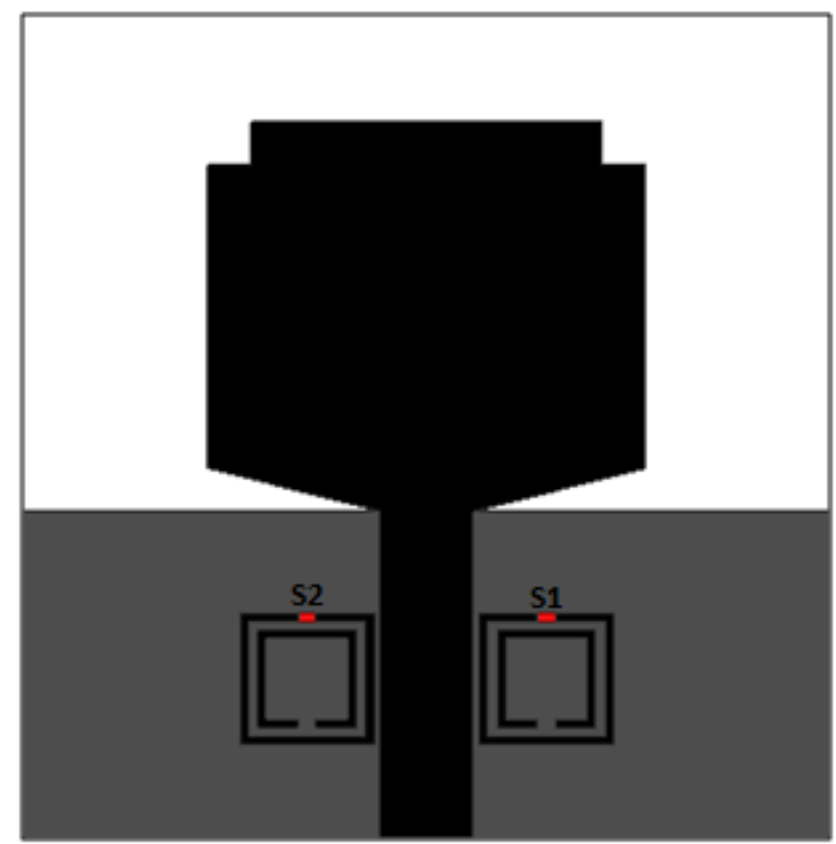

Figure 9. Design of reconfigurable band notches antenna.

Depending on the state of a switch, the corresponding splitring resonator does or does not induce a band notch. When the Switch is OFF, the split-ring resonator (SRR) causing a notch in its design band.

When the switch S1 and S2 are OFF, the SRR causes a notch in the $6 \mathrm{GHz}$ band, which disappears when they are ON.

The antenna was designed and simulated using Ansoft HFSS [8], the return loss was simulated for the two cases. A prototype was fabricated (Figure 10), and the return loss was measured for the two possible operation scenarios. Figure 11 show the computed and measured return loss plots for the two switching cases. Good analogy is shown between the simulated and measured results.

For the Case 1, a notch is obtained in the $6 \mathrm{GHz}$ band when two Switches S1 and S2 are OFF. For Case 2, the two Switches S1 and S2 are ON, in this case, none of the SRR resonates, and as a result, no notch appears in the frequency response of the UWB antenna.

The normalized simulated and measured radiation patterns for Case 2, at $6 \mathrm{GHz}$, are shown in Figure 12. The omnidirectionality of the patterns is clear. For this switching case, the peak gain at $6 \mathrm{GHz}$ is $5 \mathrm{~dB}$. For Case 2, where a notch occurs in the $6 \mathrm{GHz}$ band, this gain drops to negative values due to strong reflections at the antenna's port. 


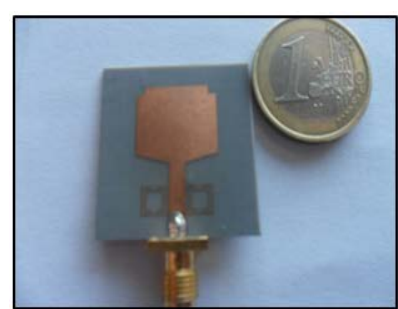

(a)

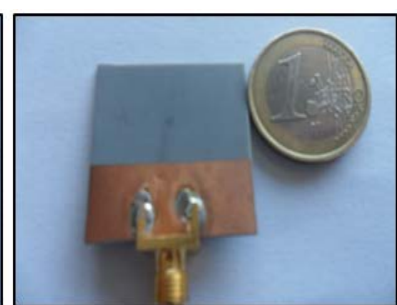

(b)

Figure 10. Photograph of the fabricated band notches antenna (a) Top plane; (b) Bottom plane.

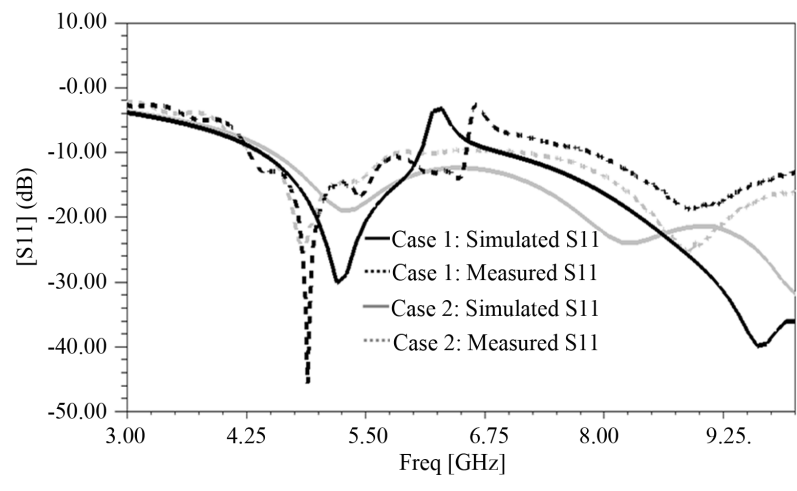

Figure 11. Simulated and measured S parameters for the reconfigurable band notches antenna.

...... E Plan: Measured

— E Plan : Simulated

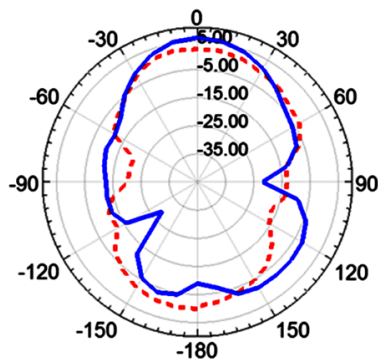

..... H Plan: Measured

_ H Plan: Simulated

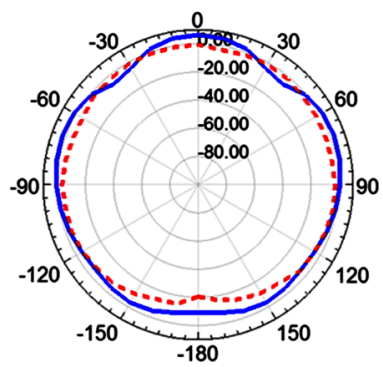

Figure 12. Simulated \& measured radiations pattern at $6 \mathrm{GHz}$ for the Case 2 in the $\mathrm{E}$, and $\mathrm{H}$ plane.

\section{Conclusion}

In this paper, a cognitive radio antenna was proposed. The design is based on a band-stop filter, which is integrated into a wideband monopole antenna. The antenna has a UWB response, and it has configurable band notches that are induced by SRRs, and controlled by electronic switches mounted over the SRRs. The antenna with different configuration of switches is fabricated and measured. The simulated and measured S parameter, radiation patterns, and peak gains of the proposed antenna are given and discussed. A credible analogy between simulated and measured results is attained. The proposed antenna can be operated in UWB cognitive radio systems. In the future works, we will investigate the real switches, such as PIN diodes or switch circuit networks.

\section{References}

[1] Mitola, J. and Maguire, G.Q. (1999) Cognitive Radio: Making Software Radios More Personal. IEEE Personal Communications, 6, 13-18. http://dx.doi.org/10.1109/98.788210 
[2] FCC (2002) Report of the Spectrum Efficiency Working Group. FCC Spectrum Policy Task Force, Technical Report.

[3] Ebrahimi, E., Kelly, J.R. and Hall, P.S. (2009) A Reconfigurable Narrowband Antenna Integrated with Wideband Monopole for Cognitive Radio Applications. IEEE Antennas and Propagation Society International Symposium (APSURSI).

[4] Gardner, P., Hamid, M.R., Hall, P.S., Kelly, J., Ghanem, F. and Ebrahimi, E. (2008) Reconfigurable Antennas for Cognitive Radio: Requirements and Potential Design Approaches. Proceedings of the IET Seminar on Wideband, Multiband Antennas and Arrays for Defence or Civil Applications, London, March, 89-94.

[5] Zhang, Y., et al. (2008) Planar Ultrawideband Antennas with Multiple Notched Bands Based on Etched Slots on the Patch and/or Split Ring Resonators on the Feed Line. IEEE Transactions on Antennas and Propagation, 56, 30633068. http://dx.doi.org/10.1109/TAP.2008.928815

[6] Pendry, J.B., Holden, A.J., Robbins, D.J. and Stewart, W.J. (1999) Magnetism from Conductors and Enhanced Nonlinear Phenomena. IEEE Transactions on Microwave Theory and Techniques, 47, 2075-2084. http://dx.doi.org/10.1109/22.798002

[7] Al-Husseini, M., Tawk, Y., Christodoulou, C.G., Kabalan, K.Y. and El-Hajj, A. (2011) Design of an Antenna Wit Reconfigurable Band Rejection for UWB Cognitive Radio. PIERS Conference, Marrakesh, March.

[8] Ansoft HFSS, Pittsburg, USA. 
Scientific Research Publishing (SCIRP) is one of the largest Open Access journal publishers. It is currently publishing more than 200 open access, online, peer-reviewed journals covering a wide range of academic disciplines. SCIRP serves the worldwide academic communities and contributes to the progress and application of science with its publication.

Other selected journals from SCIRP are listed as below. Submit your manuscript to us via either submit@scirp.org or Online Submission Portal.
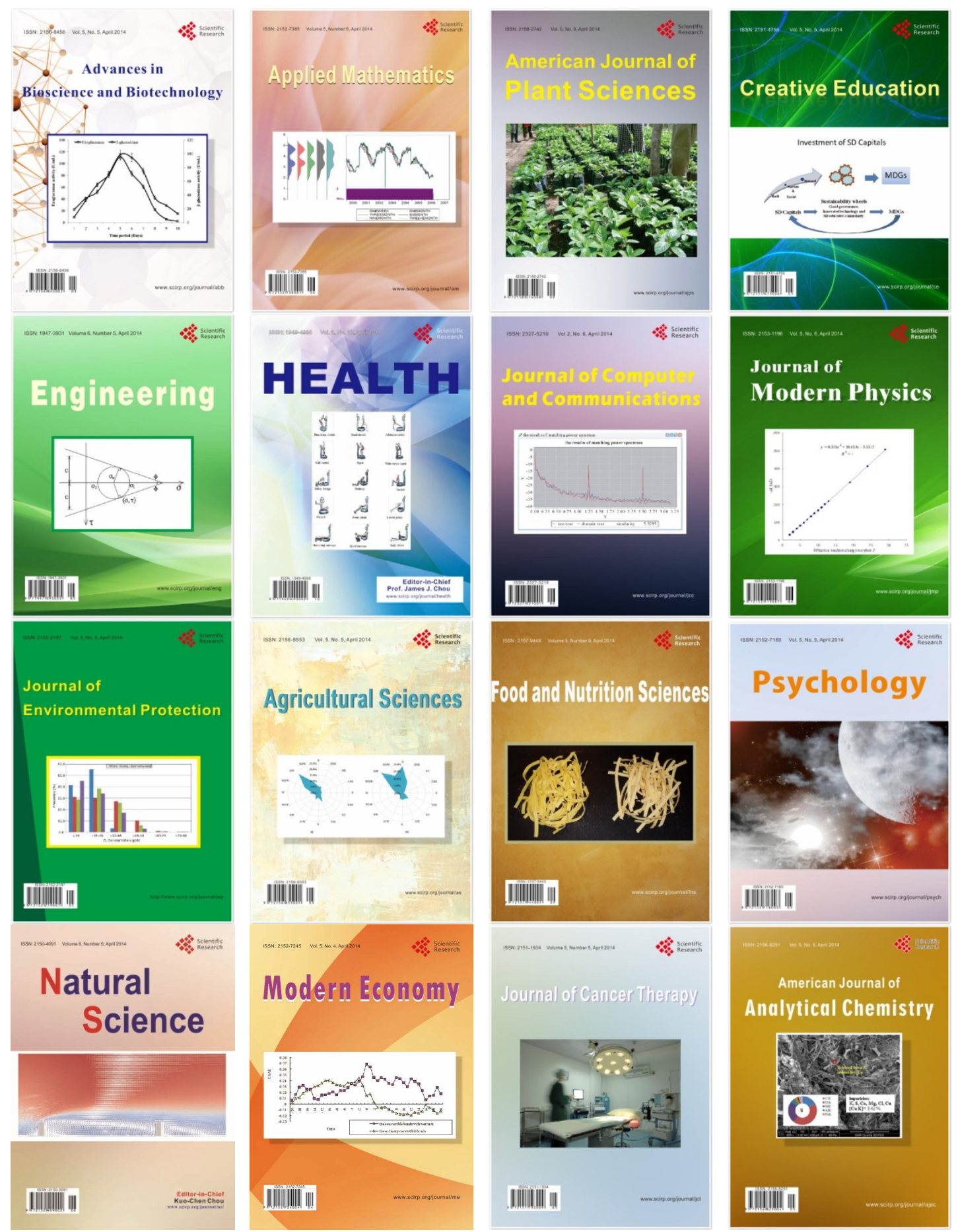